\title{
SABERES DA TRADIÇÃO: RELATOS ETNOGRÁFICOS DE VAQUEIROS SOBRE O USO DE RECURSOS NATURAIS NO TRATAMENTO DE AFECÇÕES DECORRENTES DA "PEGA DE BOI", AGRESTE PERNAMBUCANO - BRASIL
}

\author{
TRADITIONAL KNOWLEDGE: ETHNOGRAPHIC REPORTS FROM COWBOYS \\ ABOUT NATURAL RESOURCES TO TREAT AFFECTIONS DUE TO "PEGA DE BOI", \\ AGRESTE PERNAMBUCANO - BRAZIL
}

Letícia Barbosa de QUEIROZ1; Karla Patrícia de Oliveira LUNA²; Érica Caldas Silva de OLIVEIRA²*
${ }^{1}$ Graduação em Biologia/UEPB leticiabqueiroz@ hotmail.com; ${ }^{2}$ Professora do Departamento de Biologia, UEPB, Campus I,erica.caldas_8@hotmail.com (*autor para contato); karlaceatox@yahoo.com.br

Universidade Estadual da Paraíba. Rua: Baraúnas, nº 351, Universitário, Campina Grande - PB, CEP: 58.429-500.

\begin{abstract}
RESUMO: A figura do vaqueiro, cantada em verso e prosa, representa para além da tradição um ícone da conquista dos sertões nordestinos. Homem forte que desbravou as áridas terras e vegetação da caatinga à procura do gado que se perdia nos sertões. Associada à figura do vaqueiro, tem-se as competições de vaquejadas, práticas culturais destacadas na região Nordeste do Brasil. Tais práticas se modificaram ao longo do tempo, contudo, o vaqueiro ainda representa esta identidade para a região. Considerando abordagens etnográficas, objetivou-se com este estudo identificar no saber de vaqueiros quais recursos foram e são normalmente utilizados para tratamento dos animais e dos próprios vaqueiros quando estes sofrem lesões ao se exporem à vegetação xerófita e com espinhos. A técnica aplicada foi a de entrevistas abertas e livres, em que os atores sociais tiveram liberdade em expressar sua vida no campo, aplicando-se posteriormente um questionário, utilizado com a finalidade de coletar dados sociais dos entrevistados. Os resultados apresentados revelaram que os vaqueiros têm um saber apreendido à medida em que exercem seus ofícios e fazem uso de plantas, animais e outros recursos para tratar suas lesões, bem como dos animais que se machucam durante a pega do boi. Entre as plantas mais citadas, destacam-se: Mimosa tenuiflora (Willd.) Poir (jurema-preta) e Pilosocereus gounellei (A. Webwr. ex K. Schum.) Bly. ex Rowl. (alastrado). A banha de Rhinella jimi (Stevaux, 2002), "sapo cururu", é citada como cicatrizante pelos entrevistados. Com base na abordagem da pesquisa é possível perceber que o ofício de vaqueiro ainda é muito presente e bastante representativo região Nordeste do Brasil.
\end{abstract}

Palavras-chave: festa de apartação; tradição; vaquejadas.

\begin{abstract}
The figure of the cowboy, sung in verse and prose, represents beyond the tradition, an icon of the conquest of northeastern hinterland. Strong man who grub arid lands and vegetation of Caatinga, looking for the lost cattle in the hinterlands. Associated to the cowboy figure are the "vaquejadas" contests, cultural pratices relevant in Northeastern Brazil, those pratices have been changed through the years, however, the cowboy still represents the identity of the region. Considering ethnographic approaches this work aimed to identify, through the cowboys knowledge, what resources were and still are normally used to treat, in animals and themselves, the lesions due to the xerophyte vegetation and thorn. The technique applied used open free interviews were the social actors felt free to express their lives in the country, after that a questionnaire was applied to collect social data from the interviewed. The results showed that the cowboys have a great knowledge apprehended as they execute their work and use the plants, animals and other resources to treat their lesions as well as to treat their animals, injured during the "pega de boi". Among the plants most cited we have: Mimosa tenuiflora (Willd.) Poir ("jurema-preta") and Pilosocereus gounellei (A. Webwr. ex K. Schum.) Bly. ex Rowl. ("alastrado"). The fat of "cururu" frog Rhinella jimi (Stevaux, 2002) is indicated as wound healing by the interviewed. Based on the research approach it is possible to notice that the cowboy craft is still very present and very representative in the Northeast region of Brazil.
\end{abstract}

Keywords: apartação party; tradition; vaquejadas. 


\section{INTRODUÇÃO}

Considerado uma figura emblemática da cultura nordestina, o vaqueiro representa uma entidade no processo de ocupação histórica dos sertões da região Nordeste.

O espaço de ocupação geográfica na região dá-se primeiramente pela faixa litorânea com a produção da cultura canavieira, estabelecendo importante ciclo econômico do Brasil colônia entre os séculos XVI e XVIII (FREIRE, 1967). Contudo, para o interior do Nordeste, com seus ciclos intermitentes de chuva e com uma vegetação adaptada as condições de semiaridez, desbravar estas terras se constituiu em um processo mais lento de colonização, criando estradas de boiadas, desbravando a caatinga, formação vegetal característica da região, criando os pousos e currais, como bases para o estabelecimento das primeiras boiadas.

Configurando-se como a figura humana responsável por esta lenta e esplêndida marcha mugida e aboiada pelos sertões, pela civilização do couro e depois do pastoreio (QUEIROZ, 2010).

Este homem que pode ser considerado a maior escultura viva erigida até hoje nos sertões do Nordeste e de outras regiões do Brasil; este homem que singrou cada palmo de chão à procura de pastos bons e maiores para a criação de gado vacum que, com o rebanho se avolumando, já não podia viver beirando a orla, soube que imprescindivel era, portanto, descortinar o horizonte longínquo do sertão; esta escultura humana, que ampliou a geografia da então colônia trocando o canavial pela caatinga e a roupa de algodão pela roupa de couro, de que se vestiu da cabeça aos pés; a esta escultura - figura emblemática do sertão e nordeste brasileiro -, chamo-a: O VAQUEIRO". (QUEIROZ, 2010, p. 75).

Ao dominar as técnicas da "pega do boi" o vaqueiro se torna segundo Ribeiro (1998) um ator social importante nos processos de colonização dos sertões nordestinos, aprendendo a lidar com uma natureza hostil e incerta, tratando de suas doenças e das doenças do gado quando se encontravam na caatinga fechada, a procura de reses perdidas, garrotes bravios que se desgarravam do bando, construindo um cenário de lendas e crenças históricas do vaqueiro.

Ao adentrar as matas densas ou ralas o vaqueiro também apreendeu conhecimento sobre uso de plantas, animais e outros materiais utilizados nas suas práticas de cura, uma vez que, estes vaqueiros necessitavam permanecer dias afastados de casa, construindo e transmitindo saberes que foram passados as gerações futuras. A figura tradicional do vaqueiro se encontra ainda muito presente em alguns rincões do Nordeste brasileiro. Entretanto, nos dias de hoje esse vaqueiro é também aquele que participa de encontros de vaquejada, prática da derrubada de boi, comum em festas tradicionais da região (ABVAQ, 2019).

Considerando abordagens etnográficas a pesquisa buscou analisar, na perspectiva dos vaqueiros, os meios pelos dos quais estes atores sociais cuidam de suas lesões ou de lesões nos animais resultantes da lida de seu oficio.

\section{MATERIAL E MÉTODOS}

\section{Local do Experimento}

O estudo foi realizado no período de abril a outubro de 2019, na zona urbana do município de Santa Cruz do Capibaribe ( $7^{\circ} 56^{\prime} 32^{\prime \prime} \mathrm{S}$ e $\left.36^{\circ} 13^{\prime} 54^{\prime \prime} \mathrm{O}\right)$ e zona rural do município de Brejo da Madre de Deus ( $08^{\circ} 08^{\prime} 45^{\prime \prime} \mathrm{S}$ e $\left.36^{\circ} 22^{\prime} 15^{\prime \prime} \mathrm{O}\right)$, ambos localizados no agreste pernambucano (IBGE, 2010a, 2010b). Santa Cruz do Capibaribe possui clima semiárido, do tipo BSh, com índice pluviométrico médio de 460 milímetros por ano, um dos mais baixos do Estado de Pernambuco. A temperatura média anual é de $23^{\circ} \mathrm{C}$. Brejo da Madre de Deus possui clima semiárido, do tipo $B S h / C s^{\prime} a$, com índice pluviométrico médio de $928,1 \mathrm{~mm}$ por ano e temperatura média anual de $22,3^{\circ} \mathrm{C}$.

De natureza qualitativa a presente pesquisa evidenciou valores, crenças, representações, hábitos, atitudes e opiniões (MINAYO e SANCHES, 1993), ainda se apresentando como estudo exploratório, descritivo, de caráter transversal, que possibilitou maior familiaridade com o problema, ao caracterizar um determinado grupo da população ou fenômeno, permitindo associações entre variáveis em um recorte temporal para os atores sociais pesquisados (GIL, 2008). Uma análise quantitativa foi adotada para avaliar o Valor de Uso das plantas mais utilizadas pelos vaqueiros, expresso e calculado pela seguinte formula: $\mathrm{VU}=\Sigma \mathrm{U} / n$, onde $\mathrm{U}$ representa o número de citações de uma determinada espécie e $n$ representa o número total de informantes, de acordo com Albuquerque et al. (2010). 
Foi utilizada a técnica de entrevistas abertas e livres (MOURÃO e NORDI, 2006), em que os atores sociais tiveram liberdade em expressar sua vida no campo, de como aplicavam seus saberes fitoterápicos, zooterápicos entre outros, para consigo e nos animais. Sendo posteriormente aplicado questionário com a finalidade de coletar dados sociais dos vaqueiros.

O principal critério de inclusão usado para elencar os atores sociais na pesquisa foi a idade acima de 30 anos. Tal critério buscou estabelecer por parte desse ator social um conhecimento sobre o viver do vaqueiro. Outro critério utilizado na escolha foi a experiência de práticas de vaquejada acima de 10 anos, de modo que se pudesse apreender dos saberes dos vaqueiros em vaquejadas e pegas de boi, que revelassem práticas culturais tradicionais, bem como atividades mais recentes do oficio do vaqueiro.

As conversas com os vaqueiros foram realizadas de forma individualizada, e tomaram como base a espontaneidade dos entrevistados, além disso as famílias dos vaqueiros ficaram livres para contribuir com algum conhecimento relacionado ao tema. Os questionários foram aplicados aos vaqueiros com respectivos dados sociais e indagações sobre seus conhecimentos acerca do uso de fitoterápicos ou outros recursos, em si o nos animais que apresentavam lesões decorrentes do esporte de vaquejada. A pesquisa foi submetida ao Comitê de Ética em Pesquisa da Universidade Estadual da Paraíba sob o No: 4.244.370 e cadastro na Plataforma Brasil, CAAE: 36953220.1.0000.5187

\section{RESULTADOS}

Os relatos de oito vaqueiros entrevistados, considerados especialistas em suas localidades revelaram em suas falas vivências no ofício, suas representações e práticas e suas relações com o saber apreendido para tratar a si mesmo e os animais que se ferem durante as buscas nas matas dos sertões nordestinos, ou em festas de apartação. Os atores sociais entrevistados citaram dezessete espécies vegetais, seis animais e quatro recursos minerais (Quadro 1).

Quadro 1. Recursos utilizados por vaqueiros em lesões decorrentes da "pega de boi" nos municípios de Santa Cruz do Capibaribe e Brejo da Madre de Deus, PE, Brasil, 2019.

\begin{tabular}{|c|c|c|c|c|}
\hline $\begin{array}{l}\text { Recursos } \\
\text { Naturais }\end{array}$ & $\begin{array}{c}\text { Vegetais - Nome Científico/ } \\
\text { Nome Comum }\end{array}$ & $\begin{array}{l}\text { Valor de } \\
\text { Uso }\end{array}$ & $\begin{array}{c}\text { Animais - Nome Científico/ } \\
\text { Nome Comum }\end{array}$ & Minerais/Outros \\
\hline & $\begin{array}{c}\text { Mimosa tenuiflora (Willd.) Poir } \\
\text { (jurema preta) }\end{array}$ & 0,75 & $\begin{array}{l}\text { Rhinella jimi (Stevaux, 2002) } \\
\text { (sapo cururu) }\end{array}$ & Breu \\
\hline & $\begin{array}{l}\text { Pilosocereus gounellei (A. Webwr. } \\
\text { ex K. Schum.) Bly. ex Rowl. } \\
\text { (alastrado) }\end{array}$ & 0,75 & $\begin{array}{l}\text { Crotalus durissus } \mathrm{L} . \\
\quad \text { (cascavel) }\end{array}$ & $\begin{array}{l}\text { Xexo (pedra } \\
\text { branca) }\end{array}$ \\
\hline & $\begin{array}{c}\text { Anacardium occidentale L. (cajueiro } \\
\text { roxo) }\end{array}$ & 0,62 & $\begin{array}{l}\text { Salvator merianae (Duméril } \\
\text { \& Bibron, 1839) (tejú) }\end{array}$ & Enxofre \\
\hline & Aloe vera (L.) Burm. (babosa) & 0,62 & $\begin{array}{l}\text { Sus scrofa domesticus } \\
\text { Linneaus (1758) (porco) }\end{array}$ & Querosene \\
\hline & $\begin{array}{l}\text { Cenostigma pyramidale (Tul.) } \\
\text { Gagnon \& G. P. (catingueira) }\end{array}$ & 0,5 & Ovis aries L. (carneiro) & \\
\hline & $\begin{array}{l}\text { Sideroxylon obtusifolium (Humb. ex } \\
\text { Roen. \& Schult.) T. D. Penn. } \\
\text { (quixabeira) }\end{array}$ & 0,5 & $\begin{array}{l}\text { Tropidurus hispidus (Spix, } \\
\text { 1825) (lagartixa) }\end{array}$ & \\
\hline & Ximenia americana L. (ameixa) & 0,37 & & \\
\hline & $\begin{array}{l}\text { Monteverdia rigida (Mart.), Biral } \\
\text { (bom nome) }\end{array}$ & 0,25 & & \\
\hline & $\begin{array}{l}\text { Schinus terrebinthifolius Raddi } \\
\text { (aroeira) }\end{array}$ & 0,25 & & \\
\hline & $\begin{array}{c}\text { Chenopodium ambrosioides L. } \\
\text { (mastruz) }\end{array}$ & 0,25 & & \\
\hline & Jatropha curcas L. (pinhão manso) & 0,25 & & \\
\hline & Bixa orellana L. (colorau) & 0,12 & & \\
\hline & $\begin{array}{l}\text { Manihot glaziovii (Mull. Arg.) } \\
\text { Allem. (maniçoba) }\end{array}$ & 0,12 & & \\
\hline & Cucumis anguria L. (maxixe) & 0,12 & & \\
\hline & $\begin{array}{l}\text { Commiphora leptophloeos (Mart.) J. } \\
\text { B. Gillett (imburana de cheiro) }\end{array}$ & 0,12 & & \\
\hline & Hymenaea courbaril L. (jatobá) & 0,12 & & \\
\hline & $\begin{array}{c}\text { Dipteryx odorata (Aubl.) Willd. } \\
\text { (cumarú) }\end{array}$ & 0,12 & & \\
\hline Total & 16 & & 06 & 04 \\
\hline
\end{tabular}




\section{Relatos Etnográficos}

Não foram calculados os valores de uso para as espécies animais e para recursos minerais citados, em razão do baixo número de citações destes recursos pelos atores sociais entrevistados.

\section{Ronaldo Silva (57 anos), Santa Cruz de Capibaribe, vaqueiro há mais de 30 anos}

As plantas que mais seu Ronaldo utiliza para tratar afecções no gado são: $M$. tenuiflora, A. occidentale e M. rigida: "A casca da jurema preta e do cajueiro roxo faz o chá e depois mergulha o pano e passa no animal".

\section{Leonardo Andrade (42 anos), Santa Cruz de Capibaribe, vaqueiro a mais de 30 anos}

As plantas que mais seu Leonardo utiliza para tratar afecções no gado são: $C$. pyramidale, A. vera e $P$. gounellei. Sobre estas plantas, seu Leonardo afirma que:

"Eu já nasci dentro do curral praticamente. Desde criancinha eu luto com bicho entendeu? Aí corro no mato, corro na pista de vaquejada também. E a rapa de catingueira, a gente usa quando um animal se corta no mato, e de última hora não tem outro remédio, a gente rapa a catingueira, bota em cima e estanca o sangue ou o cabelo dele mesmo. A babosa já usei muito quando um animal se "estrepa", fica pedaço de pau dentro, a gente bota o "impastro" da babosa, entendeu? Aí aquilo vai puxando até que sai o pedaço de pau. Quando um animal se "espinha" com o espinho de "lastrado", a gente abre o pé de "lastrado" e passa a "baba" em cima também que puxa os espinhos, é muito bom, é muita coisa, muita coisa mesmo".

\section{Aleixo Silva (Leu - 47 anos), Santa Cruz do Capibaribe, vaqueiro a 37 anos}

Seu Leu faz uma garrafada de B. orellana, utiliza para tratar machucado nos animais as plantas $M$. tenuiflora, M. rigida, A. vera e S. obtusifolium "baba" P. gounellei. Em sua fala, seu Leu diz que: "Só tira a casca e a entrecasca da planta do lado que o sol nasce e não tira a casca em beira de estrada, porque não presta. A rapa de catingueira e a babosa estanca o sangue e para a inflamação, aí aplica na direção do cabelo se não nasce arrepiado".

\section{Manoel Silva (Ovelha aboiador - 36 anos), Santa Cruz de Capibaribe, vaqueiro a 26 anos}

Seu Manoel não citou o uso de plantas no tratamento de animais, mas contribuiu com uma estrofe da sua música "ás vezes chega machucado/ das pancadas que levou/ mas não procura hospital/ele mesmo é o doutor/ que vaqueiro não se "enrasca"/ faz o remédio da casca/ do pau que o machucou".

\section{Inácio Silva (67 anos), Santa Cruz de Capibaribe, vaqueiro a 57 anos}

Seu Inácio Mota costuma usar várias plantas e outros recursos naturais para tratar afecções nos animais, destacando aqui a "rapa" da casca de M. glaziovii, utilizada para cortar o sangue, "rapa" das cascas de C. pyramidale, X. americana, M. tenuiflora, A. occidentale, "baba" de A. vera, "baba" $P$. gounellei. São também usadas no tratamento dos animais pedra branca (xexo branco), "banhas" de $R$. jimi, C. durissus e $S$. merianae.

As cascas de C. leptophloeos, $H$. courbaril e D. odorata foram ainda citadas em tratamentos:

"A rapa de maniçoba usa pra cortar o sangue. Para cicatrizar a ferida, coloca água de jurema preta ou de caju roxo ou da ameixa, bem curtida. A babosa cicatriza também. A rapa da catingueira, o cumaru e a casca de cedro ajudam a desinflamar o ferimento. Já para sair o espinho, corta o sapo na horizontal, tira a banha, colocando em cima do ferimento e enrola num pano e depois de 8 dias sai. A banha de teju e cascavel funciona também. A baba do alastrado puxa espinho também".

\section{Miguel Sobrinho (61 anos), Santa Cruz de Capibaribe, vaqueiro a 51 anos}

Seu Miguel citou várias plantas em preparações com água: $M$. tenuiflora, A. occidentale, $M$. rigida, $X$. americana, C. pyramidale, A. vera, S. obtusifolium e S. terrebinthifolius.

"A 'babinha' do alastrado é ótima para 'puxar' o espinho do próprio alastrado, esquenta a 'babinha', enrola com o pano, comprimindo-o".

" $O$ 'fê' do boi (tipo de uma bolsinha verde, salientando que todo animal tem) é muito bom para cicatrização também, essa 'bolsinha' tem uma espécie de líquido que ajuda a desinflamar, é só 
molhar o pano com o líquido e colocar no animal, comprimindo-o. Ou passa o líquido no ferimento e enrola com o pano".

Para quebradura, utilizava $C$. ambrosioides muído com leite. "O interessante é que na fratura, a mistura do mastruz com leite, fica um anel verde (crença). Olhe eu já coloquei numa galinha o mastruz com leite por conta da quebradura, quando eu fui matar com um ano, tava o anel verde mesmo no lugar da fratura. Outra crença, é que não pode fazer cirurgia no animal na presença de mulher menstruada".

Ainda sobre quebradura, seu Miguel fala: "O 'bréu', o qual se assemelha com uma pedra, este é pisoteado e bota na água para o animal beber. $O$ enxofre farelado é muito bom para a quebradura também, muito simples de fazer, é só misturar na ração".

\section{José Lira (72 anos), Santa Cruz de Capibaribe, vaqueiro há mais de 55 anos}

As plantas mais citadas por seu Zuzu de bem bem (como é mais conhecido) para o tratamento de machucados: A. vera, S. obtusifolium, M. tenuiflora, A. occidentale, P. gounellei, J. curcas, C. pyramidale e $C$. ambosioides. $\mathrm{O}$ vaqueiro utiliza outros produtos naturais como recurso terapêtico: chapéu de baieta, breu para a quebradura, gás de candeeiro e banha de S. scrofa domesticus.

"Usa os três juntos (quixabeira, jurema preta e cajueiro roxo) deixa curtir ou cozinhar para ajudar na cicatrização. Depois disso, passa a banha de porco, penteando o cabelo para não nascer assanhado. Para estancar o sangue, coloca leite de pinhão ou chapéu de baieta, cortando um pedaço do chapéu bem fininho e bota em cima que estanca o sangue. A rapa de catingueira também é bom para estancar sangue e amarra com um pano. Pra tirar espinho coloca a baba do alastrado. Para a quebradura é bom o breu! Amassa ele e coloca na ração ou o mastruz com leite que serve também".

\section{José Xavier (64 anos) Brejo da Madre de Deus, vaqueiro há mais de 51 anos}

Seu Zé de Inácio da luz costuma usar para o tratamento de lesões do gado os seguintes recursos: $S$. terrebinthifolius, M. tenuiflora, X. americana, S. obtusifolium, A. occidentale, P. gounellei, J. curcas, C. anguria, breu, banha de $T$. hispidus, banha de sapo e sebo de $O$. aries.

"Para cicatrizar a gente usa aroeira, jurema preta, caju roxo, ameixa, quixabeira. Para tirar espinho, a gente coloca banha de cascavel, banha de sapo, banha da lagartixa, sebo de carneiro capado e a baba do lastrado, e pra corte a gente coloca leite de pinhão em cima. Já pra quebradura, a gente usa breu e o pé de maxixe. É melhor pegar no pé as que tem menos folha e que já estão maduras. Tritura no pilão raiz com tudo, coloca água, peneira e bebe”.

\section{DISCUSSÃO}

Nos municípios de Santa Cruz de Capibaribe e de Brejo da Madre de Deus, os vaqueiros interagem diretamente com recursos de fauna, flora e minerais para o tratamento de lesões.

Os resultados das questões sociais abordadas relacionavam apenas a idade e tempo que os vaqueiros se encontravam no ofício, bem como, se os mesmos utilizavam recursos naturais como alternativas terapêuticas no tratamento dos animais quando de lesões decorrentes do esporte de vaquejada ou "pegas de boi". Deste modo, para não perder o animal o vaqueiro utiliza dos meios naturais com o objetivo de amenizar o sofrimento animal.

Em suas falas os atores sociais revelam usos de plantas e animais diversos. Salienta-se que para algumas das espécies vegetais citadas já se encontram registros de usos na farmacologia. Substâncias contidas nestas plantas, têm o efeito cicatrizante em feridas, na qual a sua aplicação se dá desde tempos longínquos, quando eram utilizados plantas e extratos vegetais, na forma de cataplasmas, com a finalidade de estancar hemorragias e favorecer a cicatrização, sendo muitas dessas plantas ingeridas, para atuação em via sistêmica (SILVA e MOCELIN, 2007).

Com relação às plantas medicinais, os achados mais importantes no presente estudo foram referentes à $P$. gounellei (alastrado) e $M$. tenuiflora (jurema-preta), espécies mais citadas pelos entrevistados para a cicatrização de afecções nos animais. A função da $P$. gounellei é induzir que o espinho que adentrou na pele do animal ou do vaqueiro seja expulso, segundo os entrevistados. $\mathrm{Na}$ pega de boi é muito comum acontecer, visto que esse esporte ocorre nas entranhas da caatinga. 
Entretanto, Nascimento (2016) afirma que para a espécie $P$. gounellei, não se encontram registros de indicação como cicatrizante em feridas.

Para M. tenuiflora (jurema-preta), Tellez e Dupoy de Guitard (1990) relataram o uso no tratamento tópico do eczema (concentração de 10\%), bem como contra as inflamações (como um pó produzido a partir da casca seca) nos seres humanos. Em um experimento semelhante, o uso da casca seca de $M$. tenuiflora mostrou-se eficiente na cicatrização de feridas (DUPOY DE GUITARD, 1990). Estudos farmacológicos demonstraram que as partes aéreas da planta possuem propriedades anti-inflamatórias (SANTANA, 2012). Todos esses trabalhos mencionados contribuem em análises de estudos pretéritos com as espécies mencionadas pelos vaqueiros, neste estudo.

As cascas de $S$. terrebinthifolius (aroeira) e do cajueiro roxo servem para a cicatrização de feridas. A casca da aroeira é usada como antinflamatório e cicatrizante natural (CARMELLO-GUERREIRO e PAOLI, 1999). A casca da A. occidentale (cajueiro roxo) tem efeito cicatrizante. Estudos em animais demonstraram a ação antinflamatória e cicatrizante da $A$. occidentale, em que as lesões foram reduzidas até a cura total, sem qualquer evidência de efeitos colaterais ou reações adversas (SCHIRATO, 2006; PAIVA, 2013), corroborando com as afirmações dos vaqueiros para com tratamento das afecções, neste estudo.

A. vera (babosa) é referida entre os atores sociais entrevistados como cicatrizante em feridas, Bieskie e De La Cruz (2005) referem a espécie para tratamento de queimaduras e como cicatrizante de feridas, em estudo realizado sobre quintais medicinais na cidade de Cuiabá - MT. Os mesmos autores destacam também o uso da espécie C. ambrosioides (matruz) no tratamento de contusões e entorses, na pesquisa ora apresentada os entrevistados relataram o uso do mastruz em fraturas, resultado que corrobora com as análises em estudos acima referidos.

Os vaqueiros entrevistados nesta pesquisa destacaram o uso do cumaru no tratamento de lesões em animais machucados durante a pega de boi. O cumaru (A. cearenses) têm como principais indicações terapêuticas o tratamento de defluxo, sinusite, coriza, tosse, bronquite, afecções pulmonares, dores reumáticas, inflamação da garganta, asma, vitiligo, edema, perturbações digestivas, dor de barriga e cólicas intestinas uterinas (SOUZA e RODRIGUES, 2016). Contudo, a espécie é também indicada em processos de desinflamação e edemas, auxiliando no tratamento das lesões (SOUZA e RODRIGUES, 2016), confirmando algumas informações apresentadas por vaqueiros pesquisados.

A espécie M. rigida (bom-nome) é referida pelos atores sociais entrevistados para uso em feridas como cicatrizante, entretanto, Lima (2010), em pesquisa sobre a ação cicatrizante da espécie para tratamento de afecções na pele, utilizando a aplicação tópica do extrato etanólico da casca nas doses de 3, 10 ou $30 \mathrm{mg} / 0,4 \mathrm{~mL}$ de creme Lanette, duas vezes ao dia, não constatou atividade cicatrizante significativa após $48 \mathrm{~h}$ da indução da ferida em ratos, ou seja, não foi capaz de aumentar a tensão de abertura das cicatrizes na pele dorsal de ratos. O que se pode observar, é que muitas vezes o saber popular não necessariamente se coaduna como o saber da academia e que as crenças tradicionais se mantem nos grupos pela força própria da tradição.

S. obtusifolium (quixabeira) é referida entre os vaqueiros entrevistados como cicatrizante em feridas. Leite (2015) refere-se à espécie com efeito antinflamatório e antioxidante, em estudo realizado sobre atividades cicatrizantes, pesquisa desenvolvida no município de Canindé de São Francisco - SE, corroborando com este estudo. Os vaqueiros destacam também a $X$. americana (ameixa) para a cicatrização, assemelhando-se a estudos de Chaves et al. (2014), que afirmam ser a espécie, uma planta amplamente utilizada em todo o Brasil para o tratamento de doenças inflamatórias e cicatrização de ferimentos cutâneos.

Algumas das espécies botânicas citadas pelos entrevistados já figuram em estudos científicos como importantes no tratamento de doenças, estes dados revelam a necessidade de se buscar nas fontes os recursos utilizados por grupos tradicionais para desenvolver pesquisas na produção de novas substâncias ativas, que fomentem as indústrias químicas e farmacêuticas.

Dentre os animais citados pelos vaqueiros em seus relatos etnográficos a utilização da "banha" é destacada. A banha de $C$. durissus é mencionada pelos vaqueiros pelo seu efeito cicatrizante. Silva (2008), em pesquisas realizadas na região amazônica com o objetivo de saber quais animais eram utilizados para fins medicinais, relata a sucuriju (Eunectes murinus) como o animal mais citado, sua gordura é utilizada em diversas enfermidades, indicada no tratamento de 'rasgadura' e 'quebradura', poderoso cicatrizante de golpes, feridas e operações. A "banha da sucuriju" tem, ainda, uso como antibiótico em processos inflamatórios, respiratórios, doenças cutâneas e em problemas circulatórios, como derrame, reumatismo e inchaço. 
Mesmo considerando grupos distintos a utilização da gordura destes répteis encontra um paralelo no uso de banhas de serpente referida pelos entrevistados nessa pesquisa. $\mathrm{O}$ fato de os sujeitos desta pesquisa referirem a banha da cascavel, diferentemente do que se relata na Amazônia, deve-se ao fato de que, no semiárido nordestino a espécie Eunectes murinus não ocorre, sendo a cascavel uma espécie endêmica local.

Outros autores, como Ferreira et al. (2009), Costa Neto (2010) e Barbosa et al. (2014), em pesquisas etnográficas realizadas no Ceará e na Bahia, referem-se ao uso da banha de cascavel para o tratamento de diversas afecções, incluindo dores, luxações e ferimentos, o que corrobora com o que foi citado pelos vaqueiros, no presente estudo.

A banha de S. scrofa domesticus "porco" teve sua utilização destacada. De acordo com os trabalhos de Burger (2003), a banha de porco, não benzoinada, é um bom excipiente, sendo esta qualidade atribuída à ação específica dos ácidos insaturados presentes nesta banha. Este composto pode induzir o crescimento da epiderme, removendo um infiltrado inflamatório discreto. Ainda com relação à banha do porco, os trabalhos de Queiroz Dias et al. (2019), identificaram uma sinergia, com ação moduladora, quando associada a antibióticos, de uma atividade antibiótica da gordura. Estes dados corroboram com os relatos dos vaqueiros, quando referem o uso cicatrizante da banha do porco.

R. jimi "sapo cururu", S. merianae "tejú", O. aries "carneiro" e T. hispidus "lagartixa" são relatadas pelos vaqueiros como recursos animais dos quais se extraem a banha para fins medicinais. Nos estudos de Dornelles et al. (2010), observou-se que na América do Sul foram detectados potentes peptídeos antimicrobianos e cicatrizantes em anuros das espécies do gênero Phyllomedusa, com destaque para $P$. bicolor, $P$. distincta, $P$. tarsius e $P$. sauvagei. Espécies de mamíferos são referidas para o tratamento de afecções em animais, como registram Da Silva Policarpo et al. (2019), em estudos sobre fauna de mamíferos usados em folk medicina por caçadores no semiárido nordestino. Barbosa et al. (2018) analisaram a utilização de animais para fins medicinais por caçadores do Nordeste brasileiro e destacam, entre outros usos, a banha de $R$. jimi "sapo cururu" e $S$. merianae "tejú" como cicatrizantes. Resultados que se alinham com os registros dos vaqueiros entrevistados.

\section{CONCLUSÕES}

Os atores sociais que compuseram o recorte amostral desta pesquisa fazem largo uso de plantas, animais e outros recursos para tratar dos animais que se machucam durante as pegas de boi.

As plantas são os recursos mais comumente utilizados, quando necessário. As cascas das plantas colocadas em água representam a forma de manipulação mais comum entre os entrevistados, tanto para ingestão quanto para uso tópico.

As banhas de animais se constituem ainda grande recurso nos tratamentos de afecções registradas pelos vaqueiros entrevistados.

\section{AGRADECIMENTOS}

A todos os vaqueiros que contribuíram com os seus saberes para a construção desta pesquisa, nossos agradecimentos.

\section{REFERÊNCIAS}

ABVAQ (Associação Brasileira de Vaquejadas). Regulamento. Disponível em: <https://www.abvaq.com.br/regulamento>. Acesso em: 15 jun 2019.

ALBUQUeRQUe, U. P.; LUCENA, R. F. P.; CUNHA, L. V. F. C. Métodos e técnicas na pesquisa etnobiológica e etnoecológica (Orgs.). Recife: NUPEEA, 2010.

BARBOSA, A.; OLIVEIRA, D. S. C.; OLIVEIRA, C. R. M. Uso tradicional da fauna silvestre do município de Lapão - Bahia. Enciclopédia Biosfera - Centro Científico Conhecer, v. 10, n. 18, p. 118-133, 2014.

BARbOSA, J. A. A.; AGUIAR, J. O.; ALVES, R. R. N. Medicinal use of animals by hunters in North Eastern Brazil. Indian Journal of Traditional Knowledge, v. 17, n. 3, p. 485-493, 2018.

BURGER, M. E. et al. Cicatrização de feridas cutâneas em ratos tratados com pomada caseira à base de plantas medicinais. Revista Brasileira de Plantas Medicinais, v. 5, n. 2, p. 91-97, 2003.

BIESKIE, I. G. C.; DE LA CRUZ, M. G. Quintais medicinais: mais saúde, menos hospitais. Cuiabá: Governo do Estado do Mato Grosso, 2005.

CARMELlO-GUERREIRO, S. M.; PAOLI, A. A. S. Morfologia e anatomia da semente de Schinus terebinthifolius Raddi (Anacardiaceae) em desenvolvimento. Revista Brasileira de Botânica, v. 22, n. 1, p. 91 98, 1999. 
CHAVES, E. M. F. et al. Um olhar sobre Ximenia americana L. e suas potencialidades. Acta Tecnológica, v. 9, n. 1, p. 70-77, 2014.

COSTA NETO, E. M. Conhecimento e usos tradicionais de recursos faunísticos por uma comunidade afrobrasileira. Resultados preliminares. Interciência, v. 25, n. 9, p. 423-431, 2014.

DA SILVA POLICARPO, I.; DUARTE, R. R. B.; MARTINS, A. K.; ALVES, R. R. N. Mammalian fauna used in flok medicine among hunters in a semiarid region of Brazil. Environment, Development and Sustainablity, v. 21, p. 1533-1542, 2019

DORNELLES, M. F; MARQUES, M. G. B; RENNER, M. F. Revisão sobre toxinas de Anura (Tetrapoda, Lissamphibia) e suas aplicações biotecnológicas. Ciência em Movimento, v. 14, n. 24, p. 31-49, 2010.

FERREIRA, F. S. et al. Animal-based folk remedies sold in public markets in Crato and Juazeiro do Norte, Ceará, Brazil. BMC Complementary and Alternative Medicine, v. 9, n. 1, p. 1-8. 2009.

FREIRE, G. Nordeste: aspectos da influência da cana sobre a vida e a paisagem do nordeste do Brasil. 4. ed. Rio de Janeiro: José Olympio, 1967.

GIL, A. C. Como elaborar projetos de pesquisa. 5. ed. São Paulo: Atlas, 2008.

IBGE. Censo demográfico: Brejo da Madre de Deus. Infográficos. Evolução populacional e pirâmide etária. 2010. Disponível em: <https://cidades.ibge.gov.br/brasil/pe/brejo-da-madre-de-deus/panorama〉. Acesso em: 15 jun 2019.

IBGE. Censo demográfico: Santa Cruz do Capibaribe. Infográficos. Evolução populacional e pirâmide etária. 2010. Disponível em: <https://cidades.ibge.gov.br/brasil/pe/santa-cruz-do-capibaribe/panorama>. Acesso em: 15 jun 2019.

LEITE, N. S. et al. Avaliação das atividades cicatrizante, anti-inflamatória tópica e antioxidante do extrato etanólico da Sideroxylon obtusifolium (quixabeira). Revista Brasileira de Plantas Medicinais, v. 17, n. 1, p. 164-170, 2015.

LIMA A. P. et al. Avaliação da atividade cicatrizante do extrato etanólico da casca da Maytenus rigida Mart. (Celastracea). Scientia Plena, v. 6, n. 3, p. 4601, 2010.

MINAYO, M. C. S.; SANCHES, O. Quantitativo-qualitativo: oposição ou complementaridade? Caderno de Saúde Pública, n. 9, v. 3, p. 239-262, 1993.

MOURÃO, J. S.; NORDI, N. Pescadores, peixes, espaço e tempo: uma abordagem etnoecológica. Interciência, v. 31, p. 358-363, 2006.

NASCIMENTO, M. W. A.; VERÍSSIMO, R. C. S. S.; BASTOS, M. L. A.; BERNARDO, T. H. L. Indicações de plantas medicinais realizadas por raizeiros para tratamento de feridas. Revista Eletrônica de Enfermagem. 2016.

QUEIROZ, W. Bahia e vaqueiros: um débito. Revista Entreideias: educação, cultura e sociedade, v. 17, p. 71-84, 2010.

QUEIROZ DIAS, D. et al. GC-MS analysis of the fixed oil from Sus scrofa domesticus Linneaus (1758) and antimicrobial activity against bacteria with veterinary interest. Chemistry and Physics of Lipids, v. 219, p. 2327, 2019.

RIBEIRO, E. M. Vaqueiros, bois e boiadeiros: trabalho, negócio e cultura na pecuária do nordeste mineiro. Estudos Sociedade e Agricultura, v. 6, n.1, p. 135-164, 1998.

ROQUE A. A. et al. Uso e diversidade de plantas medicinais da Caatinga na comunidade rural de Laginhas, município de Caicó, Rio Grande do Norte (Nordeste do Brasil). Revista Brasileira de Plantas Medicinais, v. 12, n. 1, p. 31-42, 2010.

SANTANA, D. G. Beneficial effects of the etanol extract of Caesalpinia pyramidalis on the inflammatory response and abdominal hyperalgesia in rats with acute pancreatitis. Journal of Ethnopharmacology, v. 142, p. 445-455, 2012.

SCHIRATO, G. V. Application of the polysaccharide from cashew gum in the rehabilitation of experimental cutaneous lesions in mice. In: REUNIÃO ANUAL DA SOCIEDADE BRASILEIRA DE BIOQUÍMICA E BIOLOGICA MOLECUlAR, 2003, Caxambu, MG. Anais... São Paulo: Sociedade Brasileira de Bioquímica e Biologia Molecular, 2003. p. 100.

SILVA, D. M; MOCELIN, K. R. O cuidado de enfermagem ao cliente portador de feridas sob a ótica do cuidado transcultural. Nursing, v. 9, n. 105, p. 81-88, 2007.

SOUZA, D. R; RODRIGUES, E. C. A. M. S. Plantas medicinais: indicação de raizeiros para o tratamento de feridas. Revista Brasileira em Promoção da Saúde, v. 29, n. 2, p. 197-203, 2016.

TELLEZ, P. J; DUPOY DE GUITARD, J. Preparação farmacêutica contendo extrato de Mimosa tenuiflora com propriedades regeneradoras da pele. European Patent Office, v. 349, p. 469, 1990. 